\title{
A Review on Current Food Allergy
}

\section{GANIESHA DE SILVA ${ }^{1}$ and R. A. U. J. MARAPANA ${ }^{*}$}

\author{
${ }^{1}$ Post Graduate Institute Agriculture, Department of Animal Science, Faculty of Agriculture, University of Peradeniya, \\ Peradeniya, Sri Lanka \\ ${ }^{2}$ Dept of Food Science and Technology, Faculty of Applied Sciences, University of Sri Jayewardenepura, Gangodawila, \\ Nugegoda, Sri Lanka
}

\begin{abstract}
Nowadays food allergy is recognized as an important food safety issue and it is widely debated world-wide. So, the food industry necessity takes the greatest care to assist those, who suffer allergies to select a suitable diet with confidence. Food allergy might be true food allergy or pseudo-allergy (food intolerance). The prevalence of food allergy is estimated much lower than are perceived by the public. That occurrence of food allergy has been estimated recently at 3-4\% for adults and approximately 6-8\% for young children and infants in the past decade. The most common food allergens are milk, egg, tree nut, soya, fish, some fruit (pineapple, citrus) and vegetables (tomato, mushroom) other than that food containing histamine, preservative, antioxidant, colouring, flavouring and whitening agents also cause food allergic reactions in some persons. Food allergy symptoms are unique to individual and common symptoms are nausea, abdominal pain, vomiting, diarrhea and itching. If someone misunderstanding about food allergy could result unnecessary food restriction. So, it is important to know the proper facts about this condition. The main aim of this review is to discuss the recent literature on overview discussion of current food allergy.
\end{abstract}

Keywords: Food allergy, Food safety, Symptoms, Diagnosis

\section{Introduction}

Food allergy can be simply defined as an adverse reaction to food or food component that involves the body's immune system could be defined as an abnormal clinical reaction related to ingestion of protein in the food (Anderson, 1994; Spergel and Pawlowski, 2002; Carolyn et al., 2008). Further, Spergel and Pawlowski, (2002) pointed out it could either be a true food allergy (hypersensitivity) due to an underlying immunological reaction or a pseudo-allergy (food intolerance) with which has no underlying immunological basis. The prevalence of food allergy is estimated much lower than are perceived by the public. Sloan and Powers, (1986) emphasized that 18 to $22 \%$ believe that they have a food allergy and $28 \%$ of parents suspect a food allergy in their infants and young children. However, Sampson, (1992) indicated true food allergy is estimated to affect less than two percent of the population. As said by Spergel and Pawlowski, (2002) the incidence of food allergies in adults is $1-2 \%$ whilst in children under 3 years of age it is between 5-8\%. Further Sampson and McCaskill, (1985) reported 4-8\% of young children are diagnosed with food allergies, most of which are evident in their first years of life and are often 80 to $90 \%$ children outgrow their food allergies by the age of 3 years. Some authors mentioned the prevalence of food allergy has been estimated recently at $3-4 \%$ for adults and approximately 6 $8 \%$ for young children and infants in the past decade (Hanson and Telemo, 1997; Dearman and Kimber, 2001).

In many often any adverse reaction to food is often mislabeled as a food allergy. In several instances, it is caused by microbial food poisoning, a psychological aversion to a food or intolerance to an ingredient in a food. True food allergy is

*Corresponding author, E-mail: umarapana@yahoo.com a specific form of intolerance to a food or food component that activates the immune system. An allergen sets of a chain of reactions in the immune system including the release of antibodies. According to Taylor et al., (2000) these antibodies trigger the release of body chemicals, such as histamine, which give rise to various symptoms.

\section{Factors influencing for food allergy}

Many factors affect to food allergy such as genetic factors, levels of IgE in blood, maternal tobacco smoking and maternal ingestion of highly allergenic food during the last trimester (Sampson 1997; Carolyn et al., 2008). Further, Sampson, (1997) illustrated the incidence of food allergy appears to decrease with age. Kathleen and Sylvia, (2000) mentioned allergies to foods or food components are often inherited and usually identified early in life, since the allergic phenotype is expressed soon after the interactions between immune system and allergens. And also allergen-independent environmental factors are more important in adults. The prevalence of food allergy to individual is known to vary geographically, due to differences in dietary practices (Kimber and Dearman, 2002).

\section{Pathogenesis of food allergies}

Sampson, 1997 described 3 major players' of food allergy as the allergen, gastro intestinal barrier and digestive components and the immune system. Allergic reactions can occur to virtually any food, most reactions are caused by a limited number of foods (Bousquet et al., 1998). The most common food allergens are cow milk, (caseins, whey proteins) egg, (Ovomucoid, Ovalbumin) tree nuts, (ground nuts, peanuts, walnut, hazelnut, almonds) soy foods, fish and sea foods, (shrimp, crab, lobster, cod fish, oyster, mussels, cockles) fruits, (apples, pears, cherries, citrus, peaches, pineapple) and 
vegetables, (spinach, tomatoes, celery, mushroom, manioc). Other than that food additives such as food containing histamine or releasing histamine, (fresh or canned tuna, mackerel) preservatives, (sulphites and derivatives E220 E227, nitrites E249 - E252, benzoic acid and derivatives E210 - E219, sorbic acid) antioxidants, (butyl - hydroxyanisole E 321, butyl - hydroxytoluene E 321) colourings, (tartrazine E102, yellow orange E110, azorubine E122, amaranth E123, cochineal red E124, eythrosine E127, brilliant black BN E151) flavourings, (glutamates B 550 - 553) and whitening agents (potassium bromide E 924, chlorine E 925) also cause food allergies in some persons (FAO, 1995; Lamabadusuriya, 2004). Sampson, (2004) and also Carolyn et al., 2008 are illustrated the most common causal foods are cow's milk, egg, peanut, wheat, soy, tree nuts, fish, and shellfish in young children. But in adults, the most common causal foods are shellfish, peanut, tree nuts and fish.

\section{Allergies from fish \\ Histamine is an allergenic amine formed by the decarboxylation of the amino acid histidine, which is found naturally in foods, most commonly heaty blood fish and cheese (Allan, 1997; Gunarathne et al., 1997 ). And also high levels of histamine develop when fish, such as mackerel and tuna, are not properly frozen or refrigerated. Gunarathne and Samarajeeva, (1994) emphasised in fish poisoning, spoiled tuna or other fish contain large amounts of histamine produced by contaminating bacteria can mimic an allergic reaction. For example, when the spoiled fish is consumed, symptoms develop that closely resemble an allergic reaction to food and histamine poisoning causes symptoms similar to seafood. Kottegoda, (1984) reported the allergic reaction is manifested by a number of symptoms ranging from redness of eyes to vomiting and diarrhea.}

\section{Allergies from milk}

Milk allergy is caused when the immune system reacts against one or more of the proteins found in milk. This happens due to the lack of the immune system to learn to recognize milk proteins as being harmless. Cow's milk protein allergy is more commonly found in infants and children than in adults. Host et al., (1988) reported incidence of cow milk protein allergy in children under 2 years is about $2.5 \%$. But its prevalence decreases with age (Heine et al., 2002). It is estimated that 2 to $5 \%$ of infants develop milk allergy. Up to $60 \%$ of infants allergic to cow's milk will outgrow the allergy by the age of 4 and $80 \%$ by the age of 6 . However it still leaves a significant percentage of milk allergy sufferers into adult hood. Moreover, it is possible for adults to develop a milk allergy with no childhood history of allergies. Infants have true cow milk allergy, it result abdominal pain, diarrhea, rectal bleeding, skin rash, and wheezing when given milk-based formulas. These symptoms will disappear as soon milk-based formula is removed from the diet. Soya milk is not hypoallergenic. It is used as an alternative in cow's milk allergic individuals as it contains a different range of proteins. But some hypothesized approximately $20 \%$ of individuals allergic to cow's milk will be allergic to soya milk as well (McGee, 2004).

Milk allergy is often muddled with Lactose Intolerance. Lemke and Taylor (1994), described lactose intolerance that happened when people deficient in intestinal lactase enzyme, which is needed to break down the milk sugar to lactose. When milk or other dairy products are consumed, these individuals develop nausea, gas and diarrhea. Blades, (1996) mentioned lactose intolerance is the commonest genetic disorder affecting more than half the world population. It is important source of energy during the first year of a human's life, providing almost half the total energy requirement of infants. Similarly, hard cheeses, which are low in lactose, and fermented milk products such as yoghurt are usually well tolerated.

\section{Allergies from egg}

Kemp (2007), reported egg allergy is one of the most common food allergies in infants and young children. Further mentioned, the great majority is not serious and management involves exclusion of egg from the diet and regular review with the expectation that the majority of children will outgrow the allergy by school age. Jaggi, (1985) mentioned pure albumin is a potent source of egg allergy. Taking of a raw egg by a person allergic to it, can cause a most severe reaction, including collapse and shock. Even the smell of egg's contents can cause allergic reactions in highly sensitive people. In the study of Tey and Heine, (2009) suggest that most egg-allergic children will become tolerant over time. Regular ingestion of small quantities of cooked egg in baked products is often well tolerated and may hasten tolerance development. The management of egg allergy involves dietary avoidance of eggcontaining foods, implementation of anaphylaxis precautions and ongoing monitoring for tolerance development.

\section{Allergies from nuts}

Jaggi, (1985) mentioned most of the nuts, e.g., almond, walnut can cause allergic reactions. Persons, who are allergic to them, have to avoid them and also preparations like cakes and cookies containing nuts. Crespo et al., (2006) said there was differences appearing in the frequency of nut allergy between different countries because of different dietary habits and cooking procedures. For example, in the USA and France, peanuts are one of the most frequent causes of food allergy, but in other countries, it seems to be less common. Nut allergy is an important condition because it starts at an early age, is life long and can be fatal. In its mildest form, that allergy condition can be limited to a rash, sickness and headache to swelling of the tongue and lips, whereas both tree nuts and peanuts allergy in its extreme form it can cause anaphylactic shock. About a third of persons with peanut allergy therefore have subsequent allergic reactions to tree nuts. 


\section{Allergies from soya foods}

Soya is so widely distributed in processed foods that avoidance of soya in the diet is very difficult. Soya allergy means adverse reactions to one or more of the proteins found in soya, and involves the antibody immunoglobulin $\mathrm{E}$ (IgE) of the immune system. Soya allergy may also present in breast-fed infants as a result of the soya allergen passing to the infant through the breast milk. Soya allergy is more common in children than in adults. Soya allergy occurs in 5 to $30 \%$ of individuals. Twenty to $47 \%$ of children allergic to cow's milk may also be allergic to soya protein/milk. Soya allergens are heat-stable because of that cooking and heat treatment will not destroy the allergenic potential of soya, although some proteins may be denatured (Ogawa et al., 2000).

\section{Allergies from sea food}

Lopata and Lehrer, (2009) pointed out despite the fact that seafood plays an important role in human nutrition worldwide, sustained by international trade of a variety of new seafood products. Increased production and consumption have resulted humans are allergic to many of them, highlighting the need for more specific diagnosis and treatment of seafood allergy. Asia highlights seafood as a significant sensitizer in up to $40 \%$ of children and $33 \%$ of adults. Many authors declared adverse reactions to seafood are common on a worldwide and may cause many types of symptoms that are difficult to define (Daul et al., 1993; Schmid and Wuthrich, 1997; Taylor, 2008). Taylor (2008) reported fish and crustacean shellfish are very common out of that sea food allergies. Molluscan shellfish allergies are well known but do not appear to occur as frequently. Molluscan shellfish allergies have been documented to all classes of mollusks including gastropods (e.g., limpet, abalone), bivalves (e.g., clams, oysters, mussels), and cephalopods (e.g., squid, octopus). Tropomyosin is the major allergen in many shellfish, especially crustacea and mollusks (Lehrer et al., 2003; Taylor, 2008).

\section{Allergies from gluten}

Gluten intolerance is affecting many numbers of children and adults where populations have relied for centuries on foods containing gluten and it results protracted diarrhoea, malabsorption, steatorrhoea, abdominal distension and failure to thrive are common clinical manifestations. (Van Heel and West, 2006). When babies were introduced to wheat, barley, or rye at any time in the first three months had five times the risk of developing coeliac over those exposed at 4 to 6 months. Those exposed later had a slightly increased risk relative to those exposed at 4-6 months. One researcher has suggested that up to $10-15 \%$ of persons may have some form of gluten intolerance but most of them either have no digestive-tract symptoms at all or they are so minor that go unnoticed (Collin et al., 1999). Jaggi, (1985) illustrated the treatment is avoidance of wheat in all its different preparations.

\section{Allergies from meat}

Restani et al., (2009) mentioned meat allergy is normally outgrown during the first years of life, but that it is rare in adults. Schafer, (2001) observed allergy to hazelnut, celeriac and peanuts were $11-18 \%$ whereas allergy to meat was reported in just 3\%. Beef among mammals and chicken among birds are most frequently involved. The major allergens are serum albumins and immunoglobulins, but there are a few reports of allergies to muscle proteins (actin, myosin and tropomyosin). As meat allergenicity can be reduced by various treatments (heat, homogenization and freeze-drying), the consumption of meat derivatives by children allergic to meat proteins is often permitted (Restani et al., 2009). The reported prevalence of beef allergy among children is 1.8 to $6.5 \%$ and $13-20 \%$ in cases with concomitant milk allergy (Besler and Restani, 2001a). Published studies about pork meat allergy are rare. Several allergic and even anaphylactic reactions after consumption of pork meat, kidney and gut have been described as case reports (Atanaskovic, 2002). Despite the popularity of poultry consumption Michael and Zacharisen, (2006) mentioned there are just few reports of chicken meat allergies. But diets containing low cholesterol and fat, including limiting the red meat amount, the increased consumption of poultry may have potential to increase chicken meat allergy. According to the reference lists of the Allergen Data Collections (mainly based on searches of Medline and Food Science and Technology Abstracts databases) the prevalence of allergy to chicken meat ranges from $0.6 \%$ to $5 \%$ among food allergic subjects (Besler and Restani, 2001b).

\section{Allergies from alcohol}

Alcohol Intolerance is an adverse reaction to the ingestion of alcohol caused by a deficiency of the enzyme Aldehyde Dehydrogenase (ALDH) that is needed to metabolise the alcohol into acetic acid (vinegar). Alcohol is readily absorbed from the gastrointestinal tract, however, alcohol is a toxic compound and cannot be stored and therefore, the body must oxidize it to get rid of it. Alcohol can only be oxidized in the liver, where enzymes are found to initiate the process. Some people have an alteration, called a polymorphism, in the ALDH gene which renders the enzyme inactive and makes it impossible for them to convert alcohol into acetic acid. Such persons should avoid alcohol, although they can enjoy the benefit of the antioxidants found in non-alcoholic red wine. This leads to allergy-like symptoms sensation of heat, headache, abdominal discomfort, hypotension are related to high blood acetaldehyde levels (Gonzalez et al., 2004).

\footnotetext{
Allergies from Fruit

The mother's perception of bad reactions occurring in her newborn infant during the first year of life has ranged between $20 \%$ and $28 \%$. In most of these studies, that adverse reaction was due to fruit (Foucard, 1984; Bock, 1987). Many of these reactions were due to the organic acids and the fruit sugar. So, there are some people that will experience great discomfort when they eat delicious fruit if they have allergy to specific food items. The enzyme Bromelain, which is present in pineapple and papaya, is mostly responsible for
} 
triggering allergies. Mango allergy problems are caused by a reaction to Urushiol. This substance is found in the sap of mangos. Fruit allergy causes a severe rash, poison ivy, blisters around the mouth and severe itching. In order to avoid an adverse reaction, people with allergy will have to avoid the fruit completely. Other foods to which people are commonly allergic are apples, bananas, cashew, oranges, lemons, grapefruit, mushrooms, watermelons, cucumbers, grapes, gur (not cane-sugar), mustard, radish, onions, garlic, chocolates and soft drinks (Jaggi, 1985).

\begin{abstract}
Allergies from GMO food
With increased interest in the development of novel foods including some food products derived from transgenic plants, the problem is receiving more attention. So, there is need to establish safety assessment strategies for food allergy (FAO/WHO, 2001; Ladics et al., 2003). These genetically modified crops have been modified to only a minor extent by comparison with their traditional counterparts, and the level of expression of novel proteins is quite low. Thus, consumer exposure to these novel proteins is very low and unlikely to result in allergic sensitization. Nevertheless, foods produced through agricultural biotechnology must be assessed for safety, including their potential allergenicity, before they may be approved by worldwide regulatory agencies for entry into the food supply. However, Taylor and Hefle, (2002) pointed out the adequacy of the current approach to the assessment of the potential allergenicity of foods produced through agricultural biotechnology has been the subject of considerable scientific and regulatory debate.
\end{abstract}

\section{Allergies from food additives}

Another type of food allergy is a reaction to certain products that are added to food to enhance taste, add color, or protect against the growth of microbes. While food additives pose no problems for most people, a small number of people with specific allergies may be sensitive to certain food additives such as certain colours and sulphites. Monosodium glutamate (MSG) has been used for many years as a flavor enhancer. It is the sodium salt of glutamic acid, an amino acid found naturally in the human body and in all protein-containing foods such as cheese, vegetables, meat, and milk. The U.S. FDA (1995) believes MSG is a safe food ingredient for the general public. MSG is not an allergen and there is conclusive scientific evidence that MSG does not cause or exacerbate asthma. A small number of people may experience mild and transitory symptoms to MSG. However, these short-lived responses only occur in clinical settings upon ingestion of large doses of MSG without food, and were not reproduced in retesting. Whenever MSG is added to food, Woessner and Simon (2000) described it is listed on the label as monosodium glutamate.

Sulphiting agents such as sodium and potassium metabisulphite, sodium and potassium bisulphite and sulphur dioxide play a major role in food preservation (Taylor et al., 1986). Sulphites can be added as a gas $\left(\mathrm{SO}_{2}\right)$, a spray, a medium for dipping, and is mainly added during food processing. They can act as reducing agent, bleaching agent, as an anti oxidant, processing aid and as an agent to control of enzymic and non-enzymic browning, antimicrobial action and as a variety of processing aids. In many products sulphite serve more than one purpose. Sulphites are commonly used in fresh vegetables and fruits when enzymic browning presents a serious problem (Joslyn and Braverman 1954). Sulphur powder is sometimes dusted over grapes in the weeks leading up to harvest. Other sources of metabisulphite include vinegar, pickled onions, dried fruit, or when dusted onto crustaceans and some restaurant salads or fruit salads.

Although sulphites are apparently safe for consumption by most subjects, numerous studies have described individuals with sulphite sensitivity that experience adverse reactions on ingestion of sulphiting agents. The most common complaint is asthma, although other types of adverse reactions have been reported occasionally. Sulphite-induced asthma is most likely to affect steroid dependent patients suffering from asthma (Taylor et al., 1986). They estimate that the total intake of sulphite as $\mathrm{SO}_{2}$ in about $10 \mathrm{mg} /$ capita/day, which is well below the ADI of $42 \mathrm{mg}$ for a $60 \mathrm{~kg}$ person (Anonymous, 1985). Therefore Sulfites added to all packaged and processed foods must be listed on the product label.

\section{Table 1. Acceptable Levels of sulphites in consumer goods in Sri Lanka}

\begin{tabular}{ll}
\hline Product & $\mathbf{S O}_{\mathbf{2}} / \mathbf{p p m}$ \\
\hline Fruit cordial concentrate & 70 \\
Fruit squash concentrate & 70 \\
Fruit syrup concentrate & 70 \\
Ready to serve fruit drinks & 70 \\
Chilli sauce & 100 \\
Tomato sauce & 100 \\
Jams, jellies , marmalades and preserves & 100 \\
Synthetic/artificial cordials & 70 \\
\hline
\end{tabular}

Source: Gunaratne, (1998)

\section{Food allergy symptoms}

A food allergy occurs when the immune system responds to a harmless food as if it were a threat. Many people are victims of this food allergy problem. Different people can have different and bizarre allergies. Most allergies produce uncomfortable symptoms although other allergies can cause death. People need to be very careful if they have allergies. Reactions to a food typically begin within minutes but may also occur up to 2 to $4 \mathrm{hrs}$ after eating and usually last less than one day. Clinical symptoms of adverse food reactions typically involve 
the skin, gastrointestinal tract, and respiratory system (Scott et al., 2010). But in very sensitive people, simply touching or inhaling the food may produce an allergic reaction (Novembre et al., 1988). The most common symptoms of food allergy involve the gastrointestinal tract, beginning with swelling or itching of the lips, mouth or throat. When an offending food enters the stomach, nausea, vomiting, cramping and diarrhea may occur. Itching, hives, eczema and redness of the skin, sweating, swelling of the throat, breathing difficulties, lowered blood pressure, unconsciousness and can even lead to death. Symptoms of food allergy are highly individualistic, varying in terms of degree, time, location and amount of food eaten (Sampson, 1992).

\section{Diagnosis of food allergy}

A detailed history is the most valuable tool for diagnosing food allergy. Barbara et al., (2009) mentioned, an accurate diagnosis is extremely important in particular to prevent patients from unnecessary food allergy and even potentially health threatening diets. Diagnosing a food allergy begins with a thorough medical history to identify the suspected food; the amount eaten to cause a reaction, the amount of time between food consumption and development of symptoms; how often the reaction occurs; and other detailed information. A complete physical examination and selected laboratory tests are conducted to rule out underlying medical conditions not related to food allergy (Bock, 2000; Scott et al., 2010).

In the past, a variety of investigations such as skin prick tests, atopy patch tests, radioallergosorbent test (RAST) and serum IgE levels have been used (Majamaa et al., 1999). These tests are not very helpful. Double blind, placebo controlled food challenge (DBPCFC) is considered to be the gold standard for diagnosis (Bock et al., 1984). However DBPCFC is very tedious in practice and carried out only in a few specialized centers. As mentioned before, a detailed relevant history coupled with a high degree of suspicion plays an important role in clinical situations.

\section{Management of food allergies}

Food allergy and food hypersensitivity has an impact on psychological distress including anxiety and depression and on the quality of life of children and adolescents, as well as their families. $60 \%$ of reported that food allergy significantly affected meal preparation and $49 \%$ or more indicated that food allergy affected family social activities. Forty-one percent of parents reported a significant impact on their stress levels and $34 \%$ reported that food allergy had an impact on school attendance, with $10 \%$ choosing to home school their children because of food allergy (Bollinger et al., 2006). There is no cure for food allergies. Prevention of food allergy is an area of ongoing interest and research by the Allergy and Immunology community.

Currently no drugs are available to alter the long-term course of food allergy. Strict avoidance of food allergens and early recognition and management of allergic reactions to food are important measures to prevent serious health consequences. Each elimination diet must take into account the individual's ability to tolerate the offending food, the need to avoid nutritional deficiencies, the ease of following the diet and other factors (Bock, 1982). The allergenic capacity of some food allergens is destroyed by cooking and food processing, when the proteins are denatured. Newer processing techniques, such as high-pressure treatment of foods, fermentation and enzyme treatment, can help to reduce the allergenicity of some food proteins. Moreover, allergens can be removed from oils by refining (Smith and Munoz-Furlong, 2000). The vegetarian diet, free of animal proteins and code for food additives are usually displayed on the label and labels should be checked each time the food is consumed, as product formulations sometimes change.

Muraro et al., (2002) mentioned cow's milk allergy is frequently observed during the first year of life when nutritional requirements are critical. In those cases where breast-feeding is not available, a safe and adequate substitute to cow's milk should be offered. So they concluded vegetable formulas obtained from soy and milk derived from other mammals, such as mare or donkey, homemade preparations, and elemental diet may represent valid alternatives for children with cow's milk allergy. But the choice of alternative milk should take into account the clinical profile of the child allergic to cow's milk, predominantly as concerns age, severity of symptoms, degree of sensitivity to cow's milk proteins, and any multiple food allergies. Sometime a considerable percentage of the infants with bovine protein allergy may also present allergenic reactions to soy proteins as well as to hydrolyzed milk proteins. But that is not to be underestimated. So, substitution of cow's milk protein with an alternative protein source in sensitized infants has become an art rather than a science. So, Moro et al., (2002) declared rice protein, prebiotics, and probiotics appear to be valuable alternatives giving hope for the future. Other than that cow's milk allergenicity can be reduced by different dairy processing treatments. Heat treatment denatures some of the milk proteins reducing their allergenicity. For this reason, some milk-sensitive individuals can tolerate sterilised or evaporated milk products but not pasteurised milk. Other dairy processes, such as enzymatic digesting of proteins to peptides can also reduce allergenicity potential of whey proteins. In fermented products, like yoghurt, and in cheeses, the structure of the milk proteins remains largely unchanged and hence they retain their allergenicity.

\section{Conclusion}

Food allergy is an important public health problem that affects children and adults and may be increasing in prevalence. Thus far, there are no fool-proof recommendations guiding us in preventing the development of food allergy. In general it may be useful for the mother to avoid highly allergy-provoking 
foods in her diet such as nuts, peanuts and possibly eggs in the last few months of pregnancy and while breast-feeding, an allergist may also recommend a delay in introducing such foods in the child's diet until perhaps two years of age.

Despite the risk of severe allergic reactions and even death, there is no current treatment for food allergy: the disease can only be managed by allergen avoidance or treatment of symptoms. When food allergy is diagnosed once, the only proven therapy is to avoid the offending food. A diet or eating plan to eliminate the offending food must be developed carefully. A registered dietitian can provide valuable assistance in meal planning and in suggesting alternative foods or ingredients. The industry must provide these consumers with the information necessary for them to practice such avoidance effectively. Ingredient labeling statements are the key to implementation of safe and effective avoidance diets. Manufacturers must also be aware that certain processing practices such as the use of shared equipment and the use of re-work can result in undeclared residues of allergenic foods existing in other products. And also manufacturers need addressed through the use of Good Manufacturing Practices (GMP) including the implementation of Hazard Analysis and Critical Control Point (HACCP) systems, which involve close cooperation with suppliers of the raw materials and at other points in the food supply chain.

In conclusion, food allergy is common in infants and children and also present in adults as well. Careful evaluation by an allergist followed by identification of the offending food and avoidance, as well as an emergency plan can prevent dangerous reactions from occurring and allow both the child and adult to lead a normal life. Finally can concluded research efforts should underway to identify the exact nature and sequence of amino acids in the food, and this knowledge may, in the future, be an important application of biotechnology in the development of food that do not cause allergy.

\section{Reference}

Allan A. A. N. (1997). Biogenic amines in Karish and mish cheese in Egypt. Egypt J. of Dairy Sci., 25: 337-338.

Anderson J. A. (1994). The establishment of a common language concerning adverse reactions to foods and food additives. J. Allergy Clin. Immunol. 78:140-143.

Anonymous (1985). The re-examination of the GRAS status of sulphiting agents. Bethesda, Md. Life Sciences Research Office, Federation of American Societies for Experimental Biology :, 96.

Atanaskovic M. M. (2002). Food allergy to pork meat. Allergy, 57: $960-961$.

Besler M. and Restani P. (2001a). Beef (Bos domesticus). In: Internet Symposium on Food Allergens, 3:171-184.

Barbara T., Knut B., Manjula D. and Barbara K. B. (2009). Clinical presentation and diagnosis of meat allergy in
Switzerland and southern Germany, Swiss Med Wky, 139: $264-270$.

Besler M. and Restani P. (2001b). Chicken meat (Gallus domesticus). In: Internet Symposium on Food Allergens, 3: 193-201.

Blades M. (1996). Food allergy and food intolerance. Food Sci. and Tech. Today, 10: 82-86.

Bock A. S., Sampson H. A. and Atkins F. M. (1984). Double blind placebo-controlled food challenge (DBPCFC) as an office procedure: a manual. J. Allergy Clin. Immunol., 74: $26-33$.

Bock S. A. (1987). Prospective appraisal of complaints of adverse reactions to foods in children during the first three years of life. Pediatrics, 79: 683-688.

Bock S. A. (1982). Food Allergy: A Primer for People. Boulder, Colo. A.J. Publishing Co.

Bock S. A. (2000). In vivo diagnosis: skin testing and oral challenge procedures, In: Metcalfe, D. D., Sampson, H. A., and Simon, R. A., eds. Cambridge, MA, Blackwell Science, 151-166.

Bollinger M. E., Dahlquist L. M., Mudd K. Sonntag C, Dillinger L. and McKenna K. (2006). The impact of food allergy on the daily activities of children and their families. Ann Allergy Asthma Immunol. 96:385-386.

Bousquet J., Bjorksten B., Bruijnezeel-koomen C., Hugget A., Ortolani C., Warner J. O. and Smith M. (1998). Scientific criteria and the selection of allergenic foods for product labeling, Allergy, 53: 3-21.

Carolyn D., Berdanier, Johamma Dwyer and Elaine B. Beldman (2008). Handbook of nutrition of food, CRC Press, New York, 1112- 1121.

Collin P, Kaukinen K. and Maki M. (1999). Clinical features of coeliac disease today. Dig Dis Sci., 17: 100-106.

Crespo J. F., James J. M., Fernandez-Rodriguez C. and Rodriguez J. (2006). Food allergy: nuts and tree nuts. Br. J. Nutr., 96: 95-102.

Daul C. B. Morgan J. E. and Lehrer S. B. (1993). Hypersensitivity reactions to crustacea and mollusks. Clin. Rev. Allergy, 11: 201-222.

Dearman R. J. and Kimber I. (2001). Food allergy: what are the issues? Toxicol. Lett.120: 165-170.

FAO/WHO, (2001). Evaluation of allergenicity of genetically modified foods. Report of a Joint FAO/WHO Expert Consultation on Allergenicity of Foods derived from Biotechnology, Rome, Italy.

Food and Agriculture Organization (FAO). (1995). Report of the FAO Technical Consultation on food allergies. Rome, Italy.

Foucard T. (1984). Developmental aspects of food sensitivity in childhood, Nutr. Rev., 42: 98-104.

Gonzalez-Quintela A., Vidal C. and Gude F. (2004). Alcohol, 
IgE and allergy, Addict Biol., 9:195-204.

Gunarathne S. and Samarajeeva U. (1994). Histamine and histamine producing bacteria in fish from sri lanka. Tropical Agric. Res., 6: 52-58.

Gunarathne S., Samarajeeva U., Fonseka T. S. G. and Ranjani I. V. (1997). The effect of cooking ingredients on histamine in fish, Tropical Agric. Res., 9:69-76.

Gunaratne B. M. T. C. (1998). A review of the effects of the use of sulphites in food. Sabaragamuwa University J., $1: 61-67$

Hanson L. and Telemo E. (1997). The growing allergy problem. Acta Paediatr. 86: 916-918.

Heine R. G., Elsayed S., Hosking C. S. and Hill D. J. (2002). Cow's milk allergy in infancy. Current Opinion in Allergy and Clinical Immun.. 2:217-225.

Host A., Husby S. and Ostorballe O. (1988). A prospective study of cow's milk allergy in exclusively breast-fed infants. Acta Paediatr Scand, 77: 663-670.

Jaggi O. P. (1985). Asthma and Allergies Causes, Prevention and Treatment, Orient Paperbacks, Delhi, 34 - 36.

Joslyn M. A. and Braverman J. B. S. (1954). The Chemistry and Technology of the Pre-treatment and Preservation of Fruit and Vegetable Products with Sulphor Dioxide and Sulphites. Adv. Food Res. 5:97-159.

Kathleen Mahan and Sylvia Escott - Stump, (2000). Krause's food, nutrition and diet theraty, W.B.Saunders Company, 917.

Kemp A. S. (2007). Egg allergy. Pediatr Allergy Immunol, 18: 696-702.

Kimber I. and Dearman R. J. (2002). Factors affecting the development of food allergy. Proc. Nutr. Soc., 61: 435439

Kottegoda S. R. (1984). Histamine and certain disease concepts in neural and extra neuronal events in autonomic pharmacology, Reven Press, New York , 251-255

Ladics G. S., Holsapple M. P., Astwood J. D., Kimber I, Knippels L. M, Helm R. M. and Dong W. (2003). Workshop overview: approaches to the assessment of the allergenic potential of food from genetically modified crops. Toxicol. Sci. 73: 8-16.

Lamabadusuriya S. P. (2004). Some aspects of food allergy, Sri Lanka J. of Child Health, 33: 3-5

Lehrer S. B., Ayuso R. and Reese1 G. (2003). Seafood Allergy and Allergens: A Review. J. Marine Biotech. , 5: 339-348

Lemke P. J. and Taylor S. L. (1994). Allergic reactions and food intolerances. Nutritional Food toxicology. New York, Raven Press, 117-137.

Lopata A. L. and Lehrer S. B. (2009). New insights into seafood allergy, Curr Opin Allergy Clin Immunol. 9: 270-277

Majamaa H., Moisio P. and Holm K. (1999). Cow's milk allergy: Diagnostic accuracy of skin prick and patch tests and specific IgE. Allergy, 54: 851-856.

McGee, H. (2004). Milk Biology and Chemistry. On Food and Cooking: The Science and Lore of the Kitchen. First revised ed. New York: Scribner, 14-21.

Michael C. and Zacharisen M. D. (2006). Severe allergy to chicken meat, Wisconsin Medical J., 105: 50-53

Moro G. E., Warm A., Arslanoglu S. and Miniello V. (2002). Management of bovine protein allergy: new perspectives and nutritional aspects, Ann Allergy Asthma Immunol, 89:91-96

Muraro M. A., Giampietro P. G., and Galli E. (2002). Soy formulas and nonbovine milk, Ann Allergy Asthma Immunol, 89:97-101

Novembre E., De Martino M. and Vierucci A. (1988). Foods and respiratory allergy. J Allergy Clin. Immunol. 81:10591065.

Ogawa T., Samoto M. and Takahashi K. (2000). Soybean allergens and hypoallergenic soybean products. J. Nutr. Sci. Vitaminol., 46:271-279

Restani P., Ballabio C., Tripodi S. and Fiocchi A. (2009). Meat allergy. Current Opinion in Allergy and Clinical Immunology, 9:265-269.

Sampson H. A. (1992). Food hypersensitivity: manifestations, diagnosis, and natural history. Food Technol., 46: 41-144.

Sampson H. (1997). Relationship between food-specific IgE concentrations and the risk of positive food chalanges in children and adolescents. J. Allergy Clin. Immunol., $100,444$.

Sampson H. (1997). Food Allergy. In: Kay AB (ed): Allergy and allergic diseases. London; Blackwell Science, pp. 1517-1549.

Sampson H. A. (2004). Update on food allergy. J. Allergy Clin. Immunol., 113: 805-819.

Sampson H. A. and McCaskill C. M. (1985). Food hypersensitivity and atopic dermatitis: evaluation of 113 patients. J. Pediatrics, 107:669-675.

Schafer T. (2001). Epidemiology of food allergy/food intolerance in adults: associations with other manifestations of atopy. Allergy. 56:1172-1179.

Schmid M. H. and Wuthrich B., 1997, Allergy to shrimp. A contribution to reactions after ingestion of seafood and fishes. Hautarzt. 48: 541-546.

Scott H. Sicherer M. D., Hugh A. and Sampson M. D. (2010). Food allergy. J. of Allergy and Clinical Immunology, 125: 354 .

Sloan A. E. and Powers M. E. (1986). A perspective on popular perceptions of adverse reactions to foods. J. Allergy Clin. Immunol. 78:127-132.

Smith K. J. and Munoz-Furlong A. (2000). The management of food allergy. Cambridge, M A, Blackwell Science, 
431-444.

Spergel J. M. and Pawlowski N. A. (2002). Food allergy: Mechanisms, diagnosis and management in children. Paediatr Clin North Am 49: 73-96.

Taylor S. L. (2008). Molluscan shellfish allergy, Adv. Food Nutr. Res., 54:139-177.

Taylor S. L., Hefle S. L. and Gauger B. J. (2000). Food allergies and sensitivities. Food toxicology. Boca Raton, CRC Press, 1-36

Taylor S. L. and Hefle S. L. (2002). Genetically engineered foods: implications for food allergy. Current Opinion in Allergy and Clinical Immunology, 2:249-252

Taylor S. L., Higley N. A. and Bush R. K. (1986). Sulphites in Foods: Uses, Analytical Methods, Residues, Fate, Exposure Assessment, Metabolism, Toxicity and Hyper
Sensitivity. Ad. Food. Res. 30: 1-76.

Tey D. and Heine R. G. (2009). Egg allergy in childhood: an update. Current Opinion in Allergy and Clinical Immun., 9:244-250.

US FDA (1995). Federation of American Societies for Experimental Biology (FASEB), Analysis of Adverse Reactions to Monosodium Glutamate (MSG). Prepared by the Life Sciences Research Office, FASEB, for the Center for Food Safety and Applied Nutrition, U.S. Food and Drug Administration, Bethesda, Maryland: FASEB.

Van Heel D. A. and West J. (2006). Recent advances in coeliac disease. Gut, 55: 1037-1046.

Woessner K. M. and Simon R. A. (2000). Monosodium glutamate. In: Metcalfe, D.D.; Sampson, HA, Simon, RA, eds. Food Allergy: Adverse Reactions to Foods and Food Additives (2nd edition). Cambridge, MA, Blackwell Science, 359-363. 